\title{
Assessment of the Relationship Between Adherence with Antiemetic Drug Therapy and Control of Nausea and Vomiting in Breast Cancer Patients Receiving Anthracycline-Based Chemotherapy
}

\author{
Alexandre Chan, PharmD, MPH, BCPS, BCOP; Xiu Hui Low, BSc; \\ and Kevin Yi-Lwern Yap, PhD, ARPharms
}

\begin{abstract}
BACKGROUND: There are little prevalence data in the literature on nonadherence to outpatient antiemetic regimens for prophylaxis of chemotherapy-induced nausea and vomiting (CINV). It is unclear whether adherence with outpatient antiemetic regimens is associated with better CINV control. Our previous survey research supports the work of clinical pharmacists in collaborative practice with medical oncologists in improving adherence with antiemetic therapy in women undergoing highly emetic chemotherapy for breast cancer.
\end{abstract}

OBJECTIVES: To (a) evaluate the impact of adherence to delayed antiemetics (days 2-4 following anthracycline-based chemotherapy) on CINV control in breast cancer patients after anthracycline-based chemotherapy and (b) identify patient-related factors associated with nonadherence to delayed antiemetics.

METHODS: A single-center, prospective, observational study was conducted from December 2006 to January 2011 in breast cancer patients receiving anthracycline-based chemotherapy (doxorubicin or epirubicin) and antiemetics at the National Cancer Centre Singapore (NCCS), the largest ambulatory cancer center in Singapore. Included patients were aged 21 years or older with confirmed diagnoses of breast cancer and receiving anthracycline-containing chemotherapy with antiemetics. Patients were excluded if they (a) were diagnosed with intestinal obstruction or received concurrent radiotherapy that predisposed them to nausea and vomiting, (b) had vomited in the 24 hours preceding chemotherapy, or (c) had brain metastases that would impair their judgment. Patients documented in a standardized diary their emesis events, severity of nausea, use of rescue therapy with metoclopramide, and compliance with dose instructions for antiemetic drug therapy for 5 days: day 1 was the day of chemotherapy and first day of antiemetic therapy, and day 5 was the day after completion of delayed antiemetic therapy (days 2-4). Three definitions were used to describe the CINV outcomes: (a) complete response (no emetic episodes and no rescue therapy); (b) complete protection (no emetic episodes, no rescue therapy, and no significant nausea [Likert score 2 or less]); and (c) complete control (no emetic episodes, no rescue therapy, and no nausea). The delayed (days 2-5 post-chemotherapy) phase of these endpoints was analyzed. Nonadherence was defined as missing at least 1 dose of the delayed antiemetics from the prescribed regimen. Pearson chi-square or Fisher's exact tests and multiple logistic regression analysis were used to assess the relationship between adherence and CINV outcomes.

RESULTS: Of 519 eligible patients, 88 (17.0\%) patients declined participation; 35 (6.7\%) were lost to follow-up; and another 35 (6.7\%) were excluded due to the absence of therapy with delayed antiemetics according to guideline protocol. Of the $361(69.6 \%)$ patients included in the final analysis, the mean (SD) age was 50.0 (8.9); the majority was Chinese $(80.1 \%)$ and diagnosed with stage 2 or higher breast cancer (88.1\%). A total of 152 patients $(42.1 \%)$ self-reported nonadherent use of delayed antiemetics. Among all the nonadherent patients $(n=152), 16.4 \%(n=25)$ achieved complete control; $34.2 \%(n=52)$ achieved complete protection; and $58.6 \%(n=89)$ achieved complete response, compared with rates of $26.8 \%(n=56), 39.7 \%(n=83)$, and $62.7 \%(n=131)$, respectively, for adherent patients $(n=209)$. The rate of adherence to dexamethasone, which was prescribed for all study patients, was low (62.6\%). After adjusting for potential confounders (ethnicity, educational level, and disease stage), adherent patients were more likely to achieve complete control of CINV (adjusted odds ratio $=1.74,95 \% \mathrm{Cl}=1.01-3.01, P=0.048$ ). Among the demographic and CINV risk-factor variables, higher education, alcohol consumption, and prior exposure to other (nonanthracycline-based) chemotherapy regimens were associated with nonadherence $(P<0.05)$.

CONCLUSIONS: Although $42 \%$ of breast cancer patients receiving anthracycline-based chemotherapy were nonadherent with the dose administration protocol for post-chemotherapy antiemetic therapy, there was no significant difference in control of CINV compared with adherent patients except for the category of complete CINV control, defined as no nausea, no emesis, and no use of the rescue medication metoclopramide.

J Manag Care Pharm. 2012;18(5):385-94

Copyright $\odot 2012$, Academy of Managed Care Pharmacy. All rights reserved.

\section{What is already known about this subject}

- Despite improved knowledge of the pathophysiology of chemotherapy-induced nausea and vomiting (CINV) and advances in the range of antiemetics, complete avoidance of CINV has not been achieved.

- To our knowledge, no previous research has described the impact on CINV control due to poor adherence to antiemetics. It is hypothesized that poor adherence to delayed antiemetics can lead to poor control of CINV in patients with breast cancer.

- Our previous study (Shih et al. 2009) performed at the National Cancer Centre Singapore (NCCS) found an adherence rate of approximately $65 \%$ to delayed antiemetics prescribed to 91 breast cancer patients who received adjuvant doxorubicin and cyclophosphamide from December 2006 to December 2007. The previous study found 2 factors related to acute nausea (day 1 of chemotherapy) but not delayed nausea: (a) self-report of anxiety and (b) self-report of prior history of chemotherapy-induced nausea.

- In a survey of 20 medical oncologists at NCCS by Chan et al. (2008), the majority (75\%) indicated that clinical pharmacists could provide collaborative care in improving adherence with antiemetic therapy in patients receiving highly emetic chemotherapy, since they could identify the areas of antiemetics utilization within the institution that needed refinement. 


\section{What this study adds}

- A substantial proportion of breast cancer patients (42.1\%) were nonadherent to their delayed (days 2-4) antiemetic regimens, compared with 36.3\% ( $\mathrm{n}=33 / 91)$ in our previous study (Shih et al. 2009); 91 patients from the previous study were included in the present study $(\mathrm{n}=361)$.

- Compared with the previous study by Shih et al., the present study is more representative of present clinical practice for managing CINV by examining the relationship between adherence and 3 outcome measures of the degree of control of CINV: complete response (no emesis and no rescue therapy [with metoclopramide], nausea not assessed); complete protection (no emesis and no rescue therapy, no significant nausea); and complete control (no emesis, no rescue therapy, and no nausea).

- Higher educational level, use of alcohol, and prior exposure to other (nonanthracycline-based) chemotherapy regimens were associated with greater rates of nonadherence $(P=0.006$, $P=0.021$, and $P=0.028$, respectively). Patients who were adherent to antiemetics were more likely to achieve complete control of CINV from delayed antiemetic therapy compared with nonadherent patients (adjusted odds ratio $=1.74,95 \% \mathrm{CI}=1.01-3.01$, $P=0.048$ ).

- The rate of adherence was higher for aprepitant (93.9\%) than for granisetron $(71.0 \%, P=0.003)$. The rate of adherence to dexamethasone, which was prescribed for all study patients, was low $(62.6 \%)$

$\mathrm{B}$ reast cancer is the most common malignancy in women worldwide. ${ }^{1}$ Most patients receive anthracycline-containing chemotherapy regimens, consisting of an anthracycline and cyclophosphamide, which possesses high (greater than 90\%) risk of emesis. ${ }^{2-6}$ Failure to control chemotherapyinduced nausea and vomiting (CINV) can lead to unwanted complications, such as anorexia, malnutrition, dehydration, and acid-base/electrolyte imbalances, ${ }^{7}$ which may subsequently lead to extended hospitalization stays, increased financial burden and distress, and significantly impact quality of life. ${ }^{7,8}$

Despite improved knowledge of CINV pathophysiology and advances in the range of antiemetics, complete avoidance of CINV has not been achieved., ${ }^{3,9}$ Emetogenicity of the chemotherapy regimens contributes to exacerbating one's risk of CINV. However, nonadherence to antiemetics may also play a possible role in CINV control. ${ }^{10}$ Although nonadherence to antiemetics is not well studied, nonadherence to chemotherapy has been found to be prevalent among young patients with breast cancer. ${ }^{11}$ The bulk of this nonadherent behavior is usually unintentional (e.g., forgetting to take medications). However, other factors such as medication side effects, inconvenience, and difficulty in swallowing the tablets also contribute to nonadherence. ${ }^{11}$ The extent of nonadherence to delayed antiemetics and its impact on CINV are not well documented in literature. In our previous study of adherence to delayed antiemetics, we found that patients aged 49 years or younger were less adherent to their antiemetics (55\%) than those aged 50 years or older $(75 \%)^{3}$

Many chemotherapy regimens do not lead to substantial CINV in the delayed phase. In clinical practice, many patients tend to neglect taking their delayed antiemetics until they suffer from this toxicity. They do not realize that antiemetic therapy can prevent the manifestation of CINV and its severe consequences. Nonadherence to delayed antiemetics may negatively impact CINV control. However, there is a potential for oncology pharmacists to work collaboratively with physician oncologists to address this issue of antiemetic nonadherence more effectively. In a previous study describing the perceptions of 20 medical oncologists regarding the factors influencing their prescribing of antiemetics for CINV in our institution, the majority $(75 \%)$ indicated that pharmacists' counseling in collaboration with supportive treatment care was effective for improving CINV control, since the pharmacists would be able to identify areas of antiemetics utilization that needed refinement. ${ }^{12}$ In this study, we hypothesized that poor adherence to delayed antiemetics can lead to poor control of CINV. Therefore, this study was conducted to evaluate rates of adherence to antiemetic drugs among breast cancer patients treated with anthracycline-based chemotherapy. We also aimed to identify risk factors associated with suboptimal adherence to antiemetic regimens in this population. Additionally, this follow-up study was designed to overcome the methodological flaws of a previous study that we performed. ${ }^{3}$

\section{Methods}

\section{Study Design and Patients}

The present study used a single-center, prospective, observational design and was conducted from December 2006 to January 2011 at the National Cancer Centre Singapore (NCCS). NCCS is the largest ambulatory cancer center in Singapore, and it treats two-thirds of the solid tumor patients in the country. This study was approved by the SingHealth Institutional Review Board. Signed informed consent was obtained from all patient participants.

Included patients were aged 21 years or older with confirmed diagnoses of breast cancer and receiving anthracyclinebased (doxorubicin or epirubicin) chemotherapy regimens with antiemetics (Figure 1). Patients were required to be able to read and understand English/Mandarin and to provide written consent to participate in the study. Patients were excluded if they were diagnosed with intestinal obstruction or receiving concurrent radiotherapy that predisposed them to nausea or vomiting (NV), had vomited in the 24 hours preceding chemotherapy, or had brain metastases that would impair their judgment. 


\section{FIGURE 1 Patient Selection Flowchart}

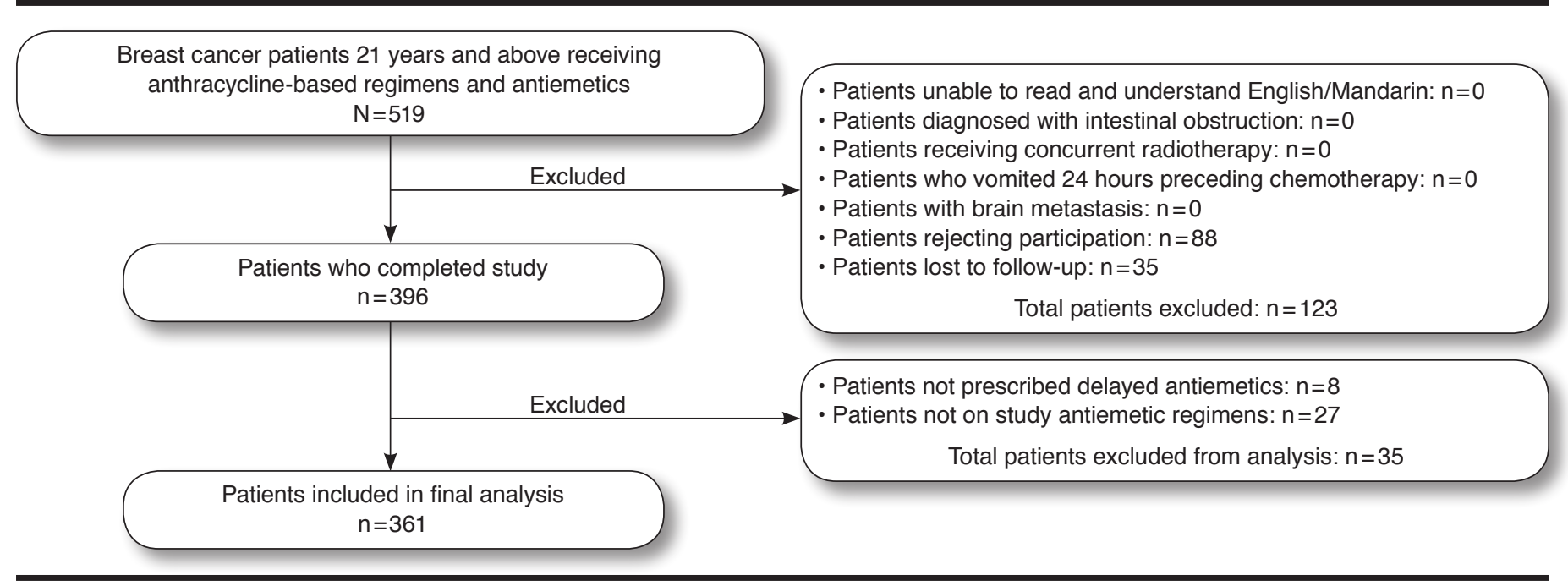

\section{Antiemetic Treatment}

Antiemetic management was regulated by a guideline established by the NCCS Pharmacy and Therapeutics Committee in which standardized prophylactic antiemetic regimens composed of a serotonin antagonist and dexamethasone were given to patients for prevention of acute and delayed CINV with anthracycline-based regimens. ${ }^{3}$ Due to the high cost of aprepitant, with most patients unable to afford expensive medications because of lack of insurance coverage, our clinical guideline differed from the American Society of Clinical Oncology guidelines (2011), which recommend aprepitant-based antiemetic regimens as first-line prophylaxis for all highly emetogenic chemotherapy regimens. ${ }^{2}$ At NCCS, aprepitant-based antiemetic regimens are recommended as first-line prophylaxis only for cisplatin-based chemotherapy regimens, but the aprepitantbased antiemetic regimen could also be prescribed based on risk factor assessments by oncology clinicians (e.g., poor control of CINV in a previous chemotherapy cycle). A l-week supply (20 tablets) of the dopamine antagonist, metoclopramide, was given as needed for rescue therapy for breakthrough emesis (Table 1).

\section{Data Collection}

On the day of chemotherapy (day 1), patients were assessed via patient interview for demographics, prescribed chemotherapy regimen and antiemetics, and CINV risk factors. Risk factors included gender, age, alcohol consumption, and history of motion sickness, morning sickness, and CINV.,13 A standardized diary (Appendix) was provided for documentation of any CINV events and antiemetic usage, starting from the day of chemotherapy for 5 days (i.e., for 1 additional day following 4 days of antiemetic therapy). This diary method to assess CINV has been used in previous research in our local cancer population..$^{14,15}$ Information obtained from patients included the (a) number of vomiting episodes (separated by at least 1 minute); (b) nausea intensity (0-10 Likert scale representing no nausea and overwhelming nausea, respectively); (c) period of day (morning, noon, evening, night) in which delayed and rescue antiemetics were administered; and (d) any unscheduled visits to clinics/hospitals due to CINV. A follow-up telephone call was made by 1 of 3 pharmacist investigators 5 days after chemotherapy to obtain this information.

\section{Outcome Measurements}

Due to the short duration of delayed antiemetic prophylaxis, adherence was defined as the completion of all delayed antiemetics on days 2-4 as prescribed. The patient self-reported antiemetic use was compared with the patient-specific dose administration instructions on the antiemetic prescription for each patient. Patients recorded for every antiemetic drug whether they had taken the drug in the morning, noon, evening, or night. Missing at least 1 dose of the delayed antiemetics from the prescribed regimen (Table 1) was defined as nonadherence. Because patients were administered their acute antiemetics by the ambulatory clinic nurses, there were no incidents of nonadherence in the acute phase.

Incidents of acute NV were defined as a Likert score of at least 1 for nausea or at least 1 vomiting episode on day 1 (i.e., the day of chemotherapy), while those for delayed NV were similarly defined for any day between days 2 to 5 days after chemotherapy. Vomiting episodes were graded by the investigators according to the National Cancer Institute Common 


\section{TABLE 1 Antiemetic Therapy Guidelines for Anthracycline-Containing Chemotherapy ${ }^{\mathrm{a}}$}

\begin{tabular}{l|l|l}
\hline Antiemetic Regimen & \multicolumn{1}{|c}{ Acute Antiemetics (Day 1) } & \multicolumn{1}{c}{ Delayed Antiemetics (Days 2-4) } \\
\hline \multirow{2}{*}{$\begin{array}{l}\text { Standard } \\
\text { antiemetic } \\
\text { regimen }\end{array}$} & IV granisetron $3 \mathrm{mg}$ (or IV ondansetron 8 mg) & Oral granisetron 1 mg daily (or oral ondansetron 8 mg twice daily) \\
\cline { 2 - 3 } & IV dexamethasone $8 \mathrm{mg}$ & Oral dexamethasone 4 mg twice daily \\
\cline { 2 - 3 } $\begin{array}{l}\text { Aprepitant-based } \\
\text { antiemetic } \\
\text { regimen }\end{array}$ & Oral metoclopramide $20 \mathrm{mg}$ up to 4 times daily when necessary & \\
\cline { 2 - 3 } & Oral aprepitant $125 \mathrm{mg}$ & Oral aprepitant $80 \mathrm{mg}$ (days 2-3) \\
\cline { 2 - 3 } & IV dexamethasone $8 \mathrm{mg}$ & Oral dexamethasone 4 mg twice daily \\
\hline
\end{tabular}

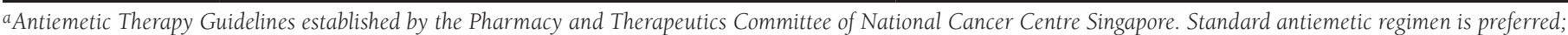
however, aprepitant-based antiemetic regimen is given to patients who experienced CINV in a previous chemotherapy cycle.

$C I N V=$ chemotherapy-induced nausea and vomiting; IV=intravenous; $m g=$ milligram.

Terminology Criteria for Adverse Events (version 3), based on the patient descriptions reported during the telephone calls. ${ }^{16}$ Self-rated nausea intensity scores were categorized as 0 (none), 1-3 (mild), 4-6 (moderate), and 7-10 (severe). ${ }^{3}$

Three composite endpoints were used for the analysis of CINV outcomes: ${ }^{17-19}$ (a) complete response (no emetic episodes and no rescue therapy); (b) complete protection (no emetic episodes, no rescue therapy, and no significant nausea [Likert score 2 or less]); and (c) complete control (no emetic episodes, no nausea, and no rescue therapy). These endpoints were stricter and more clinically relevant than the simpler outcomes of "nausea" and "vomiting" that were used in our previous study; the present study's outcomes accounted for use of the prescribed rescue antiemetic (i.e., metoclopramide). The main difference among these endpoints was the degree of nausea severity-complete response accounted only for vomiting, complete protection accounted for nausea scores of 2 or less, and complete control accounted for no nausea (i.e., scores of 0 ). The delayed (days 2-5 post-chemotherapy) phase of these endpoints was analyzed, since there were no incidents of nonadherence in the acute phase.

For purposes of determining the associations between adherence and the CINV endpoints, the proportions of patients who were adherent and nonadherent to their antiemetics and also achieved the composite endpoints were calculated using the following formulae:

Proportion of adherent patients with delayed CINV endpoint (complete response, complete protection, complete control) on an antiemetic regimen (standard, aprepitantbased, or both)=number of adherent patients on that regimen with delayed CINV endpoint $\div$ total number of adherent patients on that regimen $\times 100 \%$

Proportion of nonadherent patients with delayed CINV endpoint (complete response, complete protection, complete control) on an antiemetic regimen (standard, aprepitant-based, or both) $=$ number of nonadherent patients on that regimen with delayed CINV endpoint $\div$ total number of nonadherent patients on that regimen $\times 100 \%$

\section{Statistical Analysis}

Patient demographics and clinical characteristics were reported as frequencies and percentages (categorical variables) and medians and ranges (continuous variables). Pearson's chi-square or Fisher's exact tests were utilized to assess associations between medication adherence and clinical outcomes. Variables with 2 -sided $P$ values $\leq 0.2$ in bivariate analysis were selected for multivariable logistic regression to adjust for any characteristics that were potential confounders of the CINV endpoints. To assess the relationships between the CINV endpoints and predictors that were measured at a nominal level, Pearson chisquare tests and Fisher's exact tests were performed, whereas for predictors measured at an ordinal level, chi-square linearby-linear association tests were performed. Statistical significance was defined as $P \leq 0.05$, and analyses were performed using SPSS version 19.0 (IBM SPSS, Armonk, NY).

\section{Results}

\section{Patient Characteristics}

A total of 519 patients were potentially eligible for the study. Eighty-eight (17.0\%) patients declined participation (Figure 1). Among the 431 remaining patients, 35 (8.1\%) were lost to follow-up (e.g., could not be contacted by telephone), and another 35 (8.1\%) were excluded because they had no prescription for delayed antiemetics $(n=8)$ or were not on study antiemetic regimens $(n=27)$. Thus, $361(69.6 \%)$ patients were included in the final analysis (Table 2). The median age of patients was 50 years (range 25-75), and most were Chinese (80.1\%) and female (99.7\%). A total of 162 (44.9\%) and 112 $(31.0 \%)$ patients were in stages 2 and 3 of their cancers, respectively, and $79.2 \%(n=286)$ received the anthracycline-based chemotherapy regimen consisting of doxorubicin and cyclophosphamide. Approximately one-half (50.7\%) were receiving their first cycle of anthracycline-based chemotherapy, and almost all patients (96.1\%) had never been exposed to any other (nonanthracycline-based) chemotherapy regimens on the day of the interview. Two-thirds $(64.5 \%, \mathrm{n}=233)$ were taking only chemotherapy and antiemetics, and $10.5 \%(n=38)$ of the patients were concomitantly treated with 3 or more medications per day. 
Assessment of the Relationship Between Adherence with Antiemetic Drug Therapy and Control of Nausea and Vomiting in Breast Cancer Patients Receiving Anthracycline-Based Chemotherapy

\section{TABLE 2 Patient Characteristics ( $\mathrm{n}=361$ ) and Proportion Nonadherent with Antiemetic Therapy}

\begin{tabular}{|c|c|c|c|c|c|c|c|c|c|c|}
\hline Characteristics & $\%$ & (n) & $\begin{array}{l}\text { Nonadherent } \\
\% \quad \text { (n) }\end{array}$ & $P$ Value $^{\mathrm{a}}$ & Characteristics & $\%$ & (n) & $\begin{array}{c}\text { Nonadl } \\
\%\end{array}$ & $\begin{array}{l}\text { herent } \\
\text { (n) }\end{array}$ & $P$ Value $^{\mathrm{a}}$ \\
\hline \multicolumn{5}{|l|}{ Age (years) } & \multicolumn{6}{|c|}{ History of motion sickness } \\
\hline Median [range] & 50 & [25-75] & & & No & 77.8 & (281) & 41.3 & (116) & \multirow{2}{*}{0.552} \\
\hline 21 to 40 years & 15.8 & $(57)$ & $47.4 \quad(27)$ & \multirow{3}{*}{0.233} & Yes & 22.2 & $(80)$ & 45.0 & $(36)$ & \\
\hline 41 to 60 years & 71.7 & (259) & $42.1 \quad(109)$ & & History of morni & & & & & \\
\hline Older than 60 years & 12.5 & $(45)$ & $35.6 \quad(16)$ & & No & 40.2 & (145) & 40.0 & (58) & \multirow{4}{*}{0.504} \\
\hline Classification as a CIN & risk fa & ctor & & & Yes & 40.7 & (147) & 41.5 & (61) & \\
\hline Younger than 50 years & 51.8 & $(187)$ & $42.8 \quad(80)$ & \multirow{2}{*}{0.669} & Never pregnant & 18.8 & (68) & 47.1 & (32) & \\
\hline 50 years or older & 48.2 & (174) & $41.4 \quad(72)$ & & Missing & 0.3 & (1) & 100.0 & (1) & \\
\hline \multicolumn{5}{|l|}{ Gender } & \multicolumn{6}{|c|}{ History of chemotherapy-induced nausea } \\
\hline Female & 99.7 & $(360)$ & 41.9 (151) & \multirow[t]{2}{*}{0.421} & No & 13.0 & $(47)$ & 44.7 & $(21)$ & \multirow{3}{*}{0.427} \\
\hline Male & 0.3 & (1) & $100.0 \quad(1)$ & & Yes & 38.8 & (140) & 45.0 & (63) & \\
\hline \multicolumn{5}{|l|}{ Race } & NA & 48.2 & (174) & 39.1 & (68) & \\
\hline $\begin{array}{l}\text { Chinese } \\
\text { Malay }\end{array}$ & $\begin{array}{l}80.1 \\
11.6\end{array}$ & $\frac{(289)}{(42)}$ & $\begin{array}{ll}41.2 & (119) \\
35.7 & (15)\end{array}$ & \multirow{3}{*}{0.184} & History of chem & induce & d vomi & & & \\
\hline Indian & 4.4 & (16) & $62.5(10)$ & & No & 31.9 & (115) & 47.8 & $(55)$ & \multirow{3}{*}{0.389} \\
\hline Others & 3.9 & (14) & $57.1 \quad(8)$ & & Yes & 19.9 & $(72)$ & 40.3 & (29) & \\
\hline \multicolumn{5}{|l|}{ Marital status } & NA & 48.2 & (174) & 39.1 & $(68)$ & \\
\hline Single & 15.5 & $(56)$ & $46.4 \quad(26)$ & \multirow{5}{*}{0.252} & \multicolumn{6}{|l|}{ Cancer stage } \\
\hline Married & 76.7 & (277) & $39.7 \quad(110)$ & & Stage 1 & 12.2 & $(44)$ & 45.5 & (20) & \multirow{5}{*}{0.112} \\
\hline Widowed & 1.9 & (7) & $42.9 \quad(3)$ & & Stage 2 & 44.9 & (162) & 41.4 & $(67)$ & \\
\hline Divorced & 2.2 & (8) & $75.0 \quad(6)$ & & Stage 3 & 31.0 & (112) & 35.7 & $(40)$ & \\
\hline Missing & 3.6 & (13) & $53.8 \quad(7)$ & & Stage 4 & 6.9 & $(25)$ & 64.0 & (16) & \\
\hline \multicolumn{5}{|l|}{ Education level } & Unknown & 5.0 & (18) & 50.0 & (9) & \\
\hline No education & 5.3 & (19) & $36.8 \quad(7)$ & \multirow{6}{*}{0.006} & \multicolumn{6}{|c|}{ Prior exposure to other (nonanthracycline-based) chemotherapy regimens } \\
\hline Primary & 23.3 & (84) & $34.5(29)$ & & No & 96.1 & $(347)$ & 40.9 & $(142)$ & \multirow{2}{*}{0.028} \\
\hline Secondary & 44.6 & $(161)$ & $41.0 \quad(66)$ & & Yes & 3.9 & (14) & 71.4 & (10) & \\
\hline Pre-university & 16.6 & $(60)$ & $46.7 \quad(28)$ & & Chemotherapy c & nthrac & ycline) & & & \\
\hline Graduate & 8.0 & (29) & $51.7 \quad(15)$ & & 1 & 50.7 & (183) & 39.3 & $(72)$ & \multirow{4}{*}{0.167} \\
\hline Post-graduate & 2.2 & $(8)$ & $87.5 \quad(7)$ & & 2 & 24.4 & (88) & 42.0 & $(37)$ & \\
\hline Alcohol use & & & & & 3 & 12.7 & (46) & 45.7 & (21) & \\
\hline None & 74.2 & (268) & $38.1 \quad(102)$ & \multirow{4}{*}{0.021} & 4 or more & 12.2 & (44) & 50.0 & $(22)$ & \\
\hline $\begin{array}{l}\text { Social (less than } 1 \\
\text { drink per day) }\end{array}$ & 24.7 & (89) & $52.8 \quad(47)$ & & Number of concu & edicati & ons & & & \\
\hline Chronic (1 or more & 1.1 & (4) & $75.0 \quad(3)$ & & 0 & 64.5 & $(233)$ & 43.8 & $(102)$ & \multirow{5}{*}{0.194} \\
\hline drinks per day) & & & & & 1 & 15.8 & $(57)$ & 40.4 & $(23)$ & \\
\hline Anxiety & & & & & 2 & 9.1 & (33) & 45.5 & $(15)$ & \\
\hline No & 65.9 & $(238)$ & $41.6 \quad(99)$ & \multirow{2}{*}{0.785} & 3 & 5.8 & (21) & 38.1 & $(8)$ & \\
\hline Yes & 34.1 & (123) & $43.1 \quad(53)$ & & 4 or more & 4.7 & $(17)$ & 23.5 & (4) & \\
\hline
\end{tabular}

aPearson chi-square and Fisher's exact tests were used for variables measured on a nominal scale; chi-square linear-by-linear association tests were used for variables measured on an ordinal scale.

$C I N V=$ chemotherapy-induced nausea and vomiting; $N A=$ not applicable

\section{Antiemetic Use and Adherence}

Most patients (90.9\%) were prescribed the "standard" serotonin antagonist and corticosteroid combination for 3 days as delayed antiemetics. A total of 224 (62.0\%) patients took at least 1 dose of metoclopramide between days 1-5. Six (1.7\%) patients required an additional clinic/hospital visit for uncontrolled NV (Table 3).

Overall, 57.9\% of patients (209/361) were adherent to their delayed antiemetics. Adherence rates for the aprepitant-based regimen $(63.6 \%, 21 / 33)$ and the standard regimen $(57.3 \%$,
188/328) did not significantly differ ( $P=0.580$; Table 3$)$. However, when adherence to individual drugs was measured, the adherence rates were $93.9 \%$ (31/33) for aprepitant and $71.0 \%(233 / 328)$ for granisetron $(P=0.003)$. The rate of adherence for dexamethasone, which was prescribed to all study patients, was low $(62.6 \%, 226 / 361)$.

\section{Association of Adherence to Antiemetic Regimens with CINV Outcomes}

Among all nonadherent patients $(\mathrm{n}=152), 25(16.4 \%)$ achieved complete control; 52 (34.2\%) achieved complete protection; 


\section{TABLE 3 Antiemetic Use and Adherence}

\begin{tabular}{|c|c|}
\hline Antiemetic regimens & $\begin{array}{l}\text { Nonadherent } \\
\% \quad \text { (n) }\end{array}$ \\
\hline Standard antiemetic regimen ${ }^{\mathrm{a}, \mathrm{b}}(\mathrm{n}=328)$ & $42.7(140)$ \\
\hline Aprepitant-based regimen ${ }^{\mathrm{a}, \mathrm{b}}(\mathrm{n}=33)$ & $36.4(12)$ \\
\hline Either standard regimen or aprepitant-based $(n=361)$ & $42.1 \quad(152)$ \\
\hline \multicolumn{2}{|l|}{ Required rescue medication or visit for CINV } \\
\hline Required metoclopramide $(n=361)$ & $62.0(224)$ \\
\hline Required additional clinic/hospital visit $(\mathrm{n}=361)$ & $1.7(6)$ \\
\hline \multicolumn{2}{|l|}{ Nonadherence to individual antiemetics } \\
\hline Aprepitant alone $(n=33)$ & $6.1 \quad(2)$ \\
\hline Granisetron alone $(n=328)$ & $29.0(95)$ \\
\hline Dexamethasone alone $(\mathrm{n}=361)$ & $37.4(135)$ \\
\hline \multicolumn{2}{|c|}{$\begin{array}{l}\text { aAntiemetic Therapy Guidelines established by the Pharmacy and Therapeutics } \\
\text { Committee of the National Cancer Centre Singapore. The standard antiemetic } \\
\text { regimen is preferred; however, the aprepitant-based antiemetic regimen is given to } \\
\text { patients who experienced CINV in a previous chemotherapy cycle. } \\
\text { bThe aprepitant-based regimen includes oral aprepitant } 80 \mathrm{mg} \text { (days 2-3) and oral } \\
\text { dexamethasone } 4 \mathrm{mg} \text { twice daily as delayed antiemetics. The standard regimen } \\
\text { includes oral granisetron } 1 \mathrm{mg} \text { daily (or oral ondansetron } 8 \mathrm{mg} \text { twice daily) AND } \\
\text { oral dexamethasone } 4 \mathrm{mg} \text { twice daily as delayed antiemetics. No study patient } \\
\text { received oral ondansetron. } \\
\text { CINV=chemotherapy-induced nausea and vomiting; } m g=\text { milligram. }\end{array}$} \\
\hline
\end{tabular}

and 89 (58.6\%) achieved complete response for delayed (days 2-4) antiemetic therapy (Table 4). A significantly higher proportion of adherent than nonadherent patients achieved delayed complete control $(26.8 \%$ vs. $16.4 \%, P=0.020)$. This trend was also observed for patients on the standard antiemetic regimen $(28.2 \%$ vs. $17.9 \%, P=0.030)$. The remaining comparisons between adherent and nonadherent patients were not statistically significant $(P>0.05)$. Prior to statistical adjustment for measured confounders, patients who were adherent to their antiemetics were approximately 1.6 times as likely to achieve delayed complete control, compared with nonadherent patients (unadjusted odds ratio $[\mathrm{OR}]=1.58,95 \%$ confidence interval $[\mathrm{CI}]=1.04-2.41$ for patients on standard antiemetic regimen; $\mathrm{OR}=1.63,95 \% \mathrm{CI}=1.07-2.49$ for patients on all antiemetic regimens).

Ethnicity, educational level, and stage of disease were identified as potential confounders through bivariate analysis. After adjusting for these confounders through logistic regression analysis, patients who were adherent to antiemetics were more likely to achieve delayed complete control than those who were nonadherent (adjusted OR=1.74, 95\% CI $=1.01-3.01, P=0.048$ ).

\section{Factors Associated with Nonadherence}

Three of the measured potential CINV risk factors were associated with low adherence to antiemetics. Specifically, patients with higher educational levels $(P=0.006)$, greater consumption of alcohol $(P=0.021$ ), and prior exposure to other (nonanthracycline-based) chemotherapy regimens $(P=0.028)$ were less adherent to their antiemetics (Table 2). Rates of nonadherence

\section{TABLE 4 Association Between Adherence to Antiemetics Regimens and Clinical Endpoints}

\begin{tabular}{|c|c|c|c|c|}
\hline & & \multicolumn{3}{|c|}{ CINV Controla } \\
\hline & & $\begin{array}{c}\text { Complete } \\
\text { Control }\end{array}$ & $\begin{array}{l}\text { Complete } \\
\text { Protection }\end{array}$ & $\begin{array}{l}\text { Complete } \\
\text { Response }\end{array}$ \\
\hline \multirow{2}{*}{$\begin{array}{l}\text { Total for both } \\
\text { antiemetic } \\
\text { regimens } \\
(n=361)\end{array}$} & $\begin{array}{c}\text { Adherent } \\
\mathrm{n}=209 \\
\%(\mathrm{n})\end{array}$ & $26.8(56)^{b, c}$ & $39.7(83)$ & $62.7(131)$ \\
\hline & $\begin{array}{c}\text { Nonadherent } \\
\mathrm{n}=152 \\
\%(\mathrm{n})\end{array}$ & $16.4(25)^{b, c}$ & $34.2(52)$ & $58.6(89)$ \\
\hline \multirow{2}{*}{$\begin{array}{l}\text { Patients on } \\
\text { the standard } \\
\text { regimen } \\
(n=328)\end{array}$} & $\begin{array}{c}\text { Adherent } \\
\mathrm{n}=188 \\
\%(\mathrm{n})\end{array}$ & $28.2(53)^{d}$ & $40.4(76)$ & 61.7 (116) \\
\hline & $\begin{array}{c}\text { Nonadherent } \\
\mathrm{n}=140 \\
\%(\mathrm{n})\end{array}$ & $17.9(25)^{d}$ & $35.7(50)$ & $57.1(80)$ \\
\hline \multirow{2}{*}{$\begin{array}{l}\text { Patients on } \\
\text { the aprepitant- } \\
\text { based regimen } \\
(n=33)\end{array}$} & $\begin{array}{c}\text { Adherent } \\
\mathrm{n}=21 \\
\%(\mathrm{n})\end{array}$ & $14.3(3)$ & $33.3(7)$ & $71.4(15)$ \\
\hline & $\begin{array}{c}\text { Nonadherent } \\
\mathrm{n}=12 \\
\%(\mathrm{n})\end{array}$ & $0.0(0)$ & $16.7(2)$ & $75.0(9)$ \\
\hline
\end{tabular}

aThe degree of control of CINV was defined in 3 categories that were not mutually exclusive: (a) complete response = no emetic episodes and no rescue therapy; (b) complete protection = no emetic episodes, no rescue therapy, and no significant nausea (Likert score 2 or less); and (c) complete control=no emetic episodes, no rescue therapy, and no nausea. All comparisons were nonsignificant using a Fisher's exact test unless noted otherwise.

${ }^{b}$ Odds ratio $=1.63,95 \% C I=1.07-2.49 ; P=0.020$

cAdjusted odds ratio $=1.74,95 \% \mathrm{CI}=1.01-3.01 ; \mathrm{P}=0.048$ after adjusting for confounders (ethnicity, educational level, stage of disease) using logistic regression analysis.

${ }^{d}$ Odds ratio $=1.58,95 \% \mathrm{CI}=1.04-2.41 ; \mathrm{P}=0.030$

$C I=$ confidence interval; $C I N V=$ chemotherapy-induced nausea and vomiting

did not vary significantly by any other factor, including race ( $P=0.184)$, age group $(P=0.233)$, or disease stage $(P=0.112)$.

\section{Discussion}

To the best of our knowledge, this is the largest study to evaluate the prevalence of nonadherence to antiemetics among breast cancer patients. The CINV endpoints assessed in this study are clinically relevant, since they do not assess nausea and vomiting alone but also account for breakthrough antiemetic use. The current study overcame a major weakness in our previous study, which did not allow us to investigate the overall response to antiemetics. ${ }^{3}$ Specifically, since the present study used the composite endpoints (complete response, complete control, and complete protection), its results are more relevant to current practices of CINV management than were our previously published findings. However, it is important to note that these endpoints were not mutually exclusive. A patient who achieved complete protection (no vomiting, no rescue antiemetics, and no significant nausea) or complete 


\section{Assessment of the Relationship Between Adherence with Antiemetic Drug Therapy and Control of Nausea and Vomiting in Breast Cancer Patients Receiving Anthracycline-Based Chemotherapy}

control (no vomiting, no rescue antiemetics, and no nausea) would also, by definition, achieve complete response (no vomiting and no rescue antiemetics). Moreover, the larger sample size in this study provided a more robust analysis compared with our preliminary study. ${ }^{3}$ The endpoints used in the present study, especially compete control, are the ultimate goals of prophylactic antiemetic therapy.

Medication adherence was assessed using an "all-or-none" phenomenon-patients who missed a dose or did not take any doses at all would both be considered nonadherent. This conservative approach was realistic because antiemetics were only prescribed for a short-term basis in our study.

Our findings indicated that a substantial proportion of Asian breast cancer patients (42.1\%) were nonadherent to their antiemetics, which might have resulted in suboptimal CINV control. In the worst-case scenario, this problem could potentially lead to cessation of chemotherapy. Fortunately, this did not happen to any of our patients. However, a higher proportion of patients who adhered to their antiemetics attained better control of delayed NV. Study results supported the hypothesis that adherence to drug therapies would be associated with better health outcomes. ${ }^{20}$ Improvement of CINV outcomes was clearly demonstrated among adherent patients, even though statistical differences were not detected in the majority of the comparisons. The smaller-than-expected differences could be because CINV is a multifaceted process and can be influenced by various factors. Nevertheless, adherence is an essential factor to be considered for proper CINV management in patients on emetogenic chemotherapies.

Adherence to corticosteroids was low (63\%) in our study. This result is clinically relevant in emesis treatment because all established antiemetic guidelines emphasize the importance of prescribing dexamethasone (or corticosteroids) to prevent delayed CINV.,21,22 As an example, our institutional guidelines advocated the use of dexamethasone for antiemesis (Table 1). As such, one would expect the adherence to this antiemetic to be high. Our results indicated the contrary, and the low adherence of dexamethasone could have led to the poor CINV control observed in the study patients.

This nonadherent behavior could have been unintentional, where patients could have either forgotten their medications or misunderstood the purpose of prophylactic antiemetics. However, this behavior could also have been intentional, whereby patients chose not to take their medications due to their own experiences and perceived risks and benefits. ${ }^{23}$ Asians tend to perceive drugs as being more harmful than do Caucasians, ${ }^{24,25}$ which can result in lower adherence to treatment therapies. ${ }^{25}$ Our patients might have been averse to "steroids," since this word can invoke fear of associated side effects, ${ }^{26}$ such as insomnia, gastrointestinal symptoms, weight gain, skin rash, and depression. ${ }^{27}$ The poor adherence could also be due to a lack of confidence in antiemetic efficacy. In addition, some patients might wrongly consider CINV as a side effect that reflects chemotherapy treatment efficacy and thus expect to suffer needlessly from this toxicity. ${ }^{24}$

Clinicians should weigh the risks and benefits associated with these medications for antiemesis and counsel their patients appropriately to allay their fears regarding corticosteroid side effects. Clinicians should emphasize that CINV is not a necessary part of chemotherapy that patients have to endure, so that there will be improvements in NV control. In this respect, collaborative practice between oncology pharmacists and oncologists for antiemetic counseling may be helpful because pharmacists are able to identify the areas of antiemetics utilization that need refinement for better CINV control.

Surprisingly, adherence was inversely associated with educational level in the present study- $87.5 \%$ of post-graduates were nonadherent to their antiemetics compared with 35\%$37 \%$ of patients with primary school or no education. Our results contradict the usual association of illiteracy and low educational levels with low adherence rates. ${ }^{28}$ However, these results are similar to some studies on medication adherence of patients with other chronic diseases (e.g., hypertension and hypercholesterolemia), which suggested that less-educated patients had a higher level of trust in their physicians. ${ }^{29,30}$ For our more-educated patients, their educational status might also not have been associated with health literacy (the ability of individuals to obtain, understand, and use information to enhance and maintain health). ${ }^{31}$ Health literacy is crucial to patient adherence because patients need to understand the information before they can follow recommended treatment regimens. ${ }^{32,33}$ Adherence levels may be improved by education only if the health information that patients assimilate is in line with their health beliefs.

Previous research has suggested that patients' medication beliefs are better predictors of adherence than are clinical and sociodemographic factors. ${ }^{34}$ In Asian culture, it is believed that a strong paternalistic attitude exists in the physician's code of practice, which reflects a combination of Confucian ethos with the Hippocratic Oath; therefore, it is assumed that physicians should always be kind and devoted to caring for their patients. ${ }^{35}$ This belief could have played a predominant role in the attitudes of our less-educated patients towards taking their medications, thereby resulting in higher rates of adherence.

In contrast, the plethora of health- and medication-related information available (especially on the Internet) to our more-educated patients could have led to misinterpretations of generalized information that might have conflicted with recommendations by the health care team, ${ }^{36}$ thus increasing fears about the antiemetics and resulting in nonadherence. In the present study, 1 patient was admitted to the hospital due to suboptimal control of CINV. In such a case, an appropriate educational intervention during consultation could have allayed the patient's fears and might have possibly increased 


\section{Assessment of the Relationship Between Adherence with Antiemetic Drug Therapy and Control of Nausea and Vomiting in Breast Cancer Patients Receiving Anthracycline-Based Chemotherapy}

the patient's adherence rate. Fortunately, there were no incidents of patients ceasing or delaying chemotherapy treatment due to suboptimal CINV control.

It is imperative that health care professionals understand patients' perceptions of their medications so that they can help patients overcome barriers to adherence. Patients also need to understand the rationale for adhering to prophylactic therapy, and that nonadherence can contribute to suboptimal CINV control. Through appropriate education and counseling regarding proper antiemetic use, as well as good patient-provider communication with the health care team, CINV control can be optimized in breast cancer patients undergoing emetogenic chemotherapies. Future studies can investigate whether oncology pharmacists can add value in patient care by understanding patients' perceptions and beliefs regarding their antiemetic regimens. ${ }^{12}$

In order to minimize reporting bias, we explained the diary thoroughly to patients and ensured that they understood how to document their antiemetic consumption. Furthermore, there were no health care professionals present during the collection of adherence data so as to minimize the pressure of patients self-reporting adherence due to the "Hawthorne effect." Nonetheless, a direct assessment of health literacy might be useful for elucidating patients' understanding of antiemetics and, subsequently, their attitudes and behavior.

Awareness of the poor adherence to antiemetics within the Asian population highlights the urgency to develop effective interventions to improve medication adherence among our patients. Our previous research suggested that oncologists perceive the collaborative support between clinical pharmacists and medical oncologists in improving medication adherence as useful. ${ }^{12}$ This collaborative effort can be enhanced by various technological strategies. One proposed strategy is electronic communication technology, such as telemedicine. With the growing popularity of mobile and smartphones worldwide, telemedicine is an area that has been gaining widespread interest in recent years. It involves the use of mobile device-based interventions to monitor patients, and some systems can also provide reminders and advice to patients through short messages. To date, a number of projects have utilized telemedicine for monitoring patients with chronic diseases, such as hypertension, chronic obstructive pulmonary disease, diabetes, and even chemotherapy side effects. ${ }^{37,38}$ Such telemedicine systems are potentially useful in improving patients' adherence to antiemetics for CINV control as well. However, strong evidence of these technologies for improving the pharmaceutical care of cancer patients is still lacking. Therefore, we hope to explore the feasibility of such technologies for improving antiemetic adherence in our local population and encourage the use of such strategies among health care professionals to improve the pharmaceutical care of cancer patients in our institution.

\section{Limitations}

First, we followed the methods of our previous study in employing a standardized diary and patient self-reporting to document antiemetic medication use, since this method is practical in an outpatient setting. ${ }^{3}$ A drawback of this method would be the risk of subjectivity and recall bias in patient selfreporting. ${ }^{39}$ Additionally, the act of documenting medication use in the diary may have increased awareness of the importance of adherence, potentially biasing self-reported adherence rates upward. However, patient self-reporting is inexpensive, simple, practical, and flexible for symptom assessments in outpatient settings. ${ }^{40-42}$ Second, we did not capture the reasons for patient self-reported nonadherence behavior. Third, our results may not be generalizable to other populations, since this study was conducted within a homogeneous group of primarily Asian breast cancer patients. Fourth, this study excluded patients unable to read and understand English or Mandarin, and this exclusion eliminated patients with impaired eyesight (elderly) or literacy barriers that may contribute to nonadherence.

\section{Conclusions}

Poor adherence to prophylactic antiemetics remains a challenge to health care professionals providing cancer supportive care and can lead to suboptimal CINV control. In the present study of breast cancer patients in a large ambulatory care center, rates of complete control of CINV were higher among patients who were adherent to their antiemetics compared with nonadherent patients. Furthermore, nonadherent behavior was more prevalent among patients who had higher educational levels, greater alcohol consumption, and prior exposure to other (nonanthracycline-based) chemotherapy regimens. Future research should focus on evaluating the reasons for nonadherence to prescribed antiemetics and developing or implementing interventions to improve adherence for CINV control.

\section{Authors}

ALEXANDRE CHAN, PharmD, MPH, BCPS, BCOP, is Associate Professor, Department of Pharmacy, Faculty of Science, National University of Singapore, and Associate Consultant Clinical Pharmacist, Department of Pharmacy, National Cancer Centre Singapore, Singapore. XIU HUI LOW, BSc, is Research Assistant, Department of Pharmacy, Faculty of Science, National University of Singapore, Singapore. KEVIN YI-LWERN YAP, PhD, ARPharmS, is Assistant Professor of e-Health Innovation, Institute of Digital Healthcare, WMG, University of Warwick, Coventry, United Kingdom.

AUTHOR CORRESPONDENCE: Kevin Yi-Lwern Yap, PhD, ARPharmS, University of Warwick, Institute of Digital Healthcare, WMG, International Digital Laboratory, Coventry, CV4 7AL, United Kingdom. Tel.: +44 (0) 247615 1602; E-mail:

kevinyap.ehealth@gmail.com 


\section{Assessment of the Relationship Between Adherence with Antiemetic Drug Therapy and Control of Nausea and Vomiting in Breast Cancer Patients Receiving Anthracycline-Based Chemotherapy}

\section{DISCLOSURES}

There was no external funding of this research, and all authors reported no conflicts of interest related to the subject of this study. An abstract of this manuscript was presented as a poster at the 2011 European Multidisciplinary Cancer Congress: Integrating Basic \& Translational Science, Surgery, Radiotherapy, Medical Oncology, Advocacy \& Care in Stockholm, Sweden, on September 26, 2011.

Concept and design were performed primarily by Chan and Yap. Data were collected by Low and Yap with the assistance of acknowledged contributors Ong and Shih. Data interpretation was primarily the work of Chan, Yap, and Low. The manuscript was written primarily by Chan, Low, and Yap and revised by Chan and Yap.

\section{ACKNOWLEDGMENTS}

The authors would like to thank Vivianne Shih, PharmD, BCPS, BCOP, from the Pharmacy Department, National Cancer Centre Singapore, and Rachel Ong, BScPharm(Hon) from the Pharmacy Department, National University of Singapore, for helping with the recruitment of patients for this study.

\section{REFERENCES}

1. Ferlay J, Shin HR, Bray F, Forman D, Mathers C, Parkin DM. Estimates of worldwide burden of cancer in 2008: GLOBOCAN 2008. Int J Cancer. 2010;127(12):2893-917. Available at: http://onlinelibrary.wiley.com/ doi/10.1002/ijc.25516/full. Accessed May 15, 2012.

2. Basch E, Prestrud AA, Hesketh PJ, et al. Antiemetics: American Society of Clinical Oncology clinical practice guideline update. J Clin Oncol. 2011;29(31):4189-98. Available at: http://jco.ascopubs.org/content/29/31/4189.full. Accessed May 15, 2012

3. Shih V, Hee HS, Chan A. Clinical predictors of chemotherapy-induced nausea and vomiting in breast cancer patients receiving adjuvant doxorubicin and cyclophosphamide. Ann Pharmacother. 2009;43(3):444-52.

4. Booth CM, Clemons M, Dranitsaris G, et al. Chemotherapy-induced nausea and vomiting in breast cancer patients: a prospective observational study. J Support Oncol. 2007;5(8):374-80.

5. American Society of Clinical Oncology, Kris MG, Hesketh PJ, Somerfield MR, et al. American Society of Clinical Oncology guideline for antiemetics in oncology: update 2006. J Clin Oncol. 2006;24(18):2932-47. Available at: http://jco.ascopubs.org/content/24/18/2932.full. Accessed May 15, 2012.

6. Grunberg SM, Osoba D, Hesketh PJ, et al. Evaluation of new antiemetic agents and definition of antineoplastic agent emetogenicity—an update. Support Care Cancer. 2005;13(2):80-84. Available at: http://www.springerlink.com/content/f5rktpu2xmjktjjt/fulltext.html. Accessed May 15, 2012.

7. Schnell FM. Chemotherapy-induced nausea and vomiting: the importance of acute antiemetic control. Oncologist. 2003;8(2):187-98. Available at: http:// theoncologist.alphamedpress.org/content/8/2/187.full. Accessed May 15, 2012

8. Ballatori E, Roila F. Impact of nausea and vomiting on quality of life in cancer patients during chemotherapy. Health Qual Life Outcomes. 2003;1:46. Available at: http://dx.doi.org/10.1186/1477-7525-1-46. Accessed May 15, 2012.

9. Grunberg SM, Deuson RR, Mavros P, et al. Incidence of chemotherapyinduced nausea and emesis after modern antiemetics. Cancer. 2004;100(10): 2261-68. Available at: http://onlinelibrary.wiley.com/doi/10.1002/ cncr.20230/full. Accessed May 15, 2012.

10. Jordan K, Sippel C, Schmoll HJ. Guidelines for antiemetic treatment of chemotherapy-induced nausea and vomiting: past, present, and future recommendations. Oncologist. 2007;12(9):1143-50. Available at: http://theoncologist.alphamedpress.org/content/12/9/1143.full. Accessed May 15, 2012.

11. Atkins L, Fallowfield L. Intentional and non-intentional nonadherence to medication amongst breast cancer patients. Eur J Cancer. 2006;42(14):2271-76
12. Chan A, Shih V, Chew L. Evolving roles of oncology pharmacists in Singapore: a survey on prescribing patterns of antiemetics for chemotherapy induced nausea and vomiting (CINV) at a cancer centre. J Oncol Pharm Pract. 2008;14(1):23-29.

13. Osoba D, Zee B, Pater J, Warr D, Latreille J, Kaizer L. Determinants of postchemotherapy nausea and vomiting in patients with cancer. Quality of Life and Symptom Control Committees of the National Cancer Institute of Canada Clinical Trials Group. J Clin Oncol. 1997;15(1):116-23.

14. Yap KY-L, Yak XR, Shih V, Chui WK, Chan A. Application of unsupervised learning in clinical oncology practice-exploring anxiety characteristics in chemotherapy-induced nausea and vomiting through principal variables. J Computing. 2010;2(7):163-71. Available at: http://www.scribd.com/ doc/34833156/Application-of-Unsupervised-Learning-in-Clinical-OncologyPractice-\%E2\%80\%93-Exploring-Anxiety-Characteristics-in-ChemotherapyInduced-Nausea-and-Vomiting-thr. Accessed May 15, 2012.

15. Yap KY, Low XH, Chui WK, Chan A; Onco-Informatics Group. Computational prediction of state anxiety in Asian patients with cancer susceptible to chemotherapy-induced nausea and vomiting. J Clin Psychopharmacol. 2012;32(2):207-17.

16. National Cancer Institute. Common terminology criteria for adverse events (CTCAE) version 3.0. August 9, 2006. Available at: http://ctep. cancer.gov/protocolDevelopment/electronic_applications/docs/ctcaev3.pdf. Accessed May 15, 2012

17. Hesketh PJ, Grunberg SM, Gralla RJ, et al. The oral neurokinin-1 antagonist aprepitant for the prevention of chemotherapy-induced nausea and vomiting: a multinational, randomized, double-blind, placebo-controlled trial in patients receiving high-dose cisplatin-the Aprepitant Protocol 052 Study Group. J Clin Oncol. 2003;21(22):4112-19. Available at: http://jco.ascopubs.org/content/21/22/4112.full. Accessed May 15, 2012

18. Hesketh PJ, Younger J, Sanz-Altamira P, et al. Aprepitant as salvage antiemetic therapy in breast cancer patients receiving doxorubicin and cyclophosphamide. Support Care Cancer. 2009;17(8):1065-70.

19. Yeo W, Mo FK, Suen JJ, et al. A randomized study of aprepitant, ondansetron and dexamethasone for chemotherapy-induced nausea and vomiting in Chinese breast cancer patients receiving moderately emetogenic chemotherapy. Breast Cancer Res Treat. 2009;113(3):529-35.

20. Horwitz RI, Horwitz SM. Adherence to treatment and health outcomes. Arch Intern Med. 1993;153(16):1863-68.

21. National Comprehensive Cancer Network. NCCN clinical practice guidelines in oncology. Antiemesis v.1.2012. July 20, 2011. Available at: http:// www.nccn.org/professionals/physician_gls/PDF/antiemesis.pdf. Accessed May 15, 2012.

22. Roila F, Herrstedt J, Aapro M, et al. Guideline update for MASCC and ESMO in the prevention of chemotherapy- and radiotherapy-induced nausea and vomiting: results of the Perugia consensus conference. Ann Oncol. 2010;21(Suppl 5):v232-43. Available at: http://annonc.oxfordjournals.org/ content/21/suppl_5/v232.full. Accessed May 15, 2012.

23. Lehane E, McCarthy G. Intentional and unintentional medication nonadherence: a comprehensive framework for clinical research and practice? A discussion paper. Int J Nurs Stud. 2007;44(8):1468-77.

24. Grunberg S, Clark-Snow RA, Koeller J. Chemotherapy-induced nausea and vomiting: contemporary approaches to optimal management: proceedings from a symposium at the 2008 Multinational Association of Supportive Care in Cancer (MASCC) Annual Meeting. Support Care Cancer. Epub 2010 Jan 19 .

25. Mårdby A-C, Åkerlind I, Jörgensen T. Beliefs about medicines and selfreported adherence among pharmacy clients. Patient Educ Couns. 2007;69 (1-3):158-64.

26. Soh KB. What you need to know-medications for rhinitis-uses and abuses. Singapore Med J. 1999;40(2):120-22. 


\section{Assessment of the Relationship Between Adherence with Antiemetic Drug Therapy and Control of Nausea and Vomiting in Breast Cancer Patients Receiving Anthracycline-Based Chemotherapy}

27. Vardy J, Chiew KS, Galica J, Pond GR, Tannock IF. Side effects associated with the use of dexamethasone for prophylaxis of delayed emesis after moderately emetogenic chemotherapy. Br J Cancer. 2006;94(7):1011-15. Available at: http://dx.doi.org/10.1038/sj.bjc.6603048. Accessed May 15, 2012.

28. Sabaté E, ed. Adherence to long-term therapies: evidence for action. World Health Organization. 2003. Available at: http://apps.who.int/medicinedocs/pdf/s4883e/s4883e.pdf. Accessed May 15, 2012.

29. Senior V, Marteau TM, Weinman J. Self-reported adherence to cholesterol-lowering medication in patients with familial hypercholesterolaemia: the role of illness perceptions. Cardiovasc Drugs Ther. 2004;18(6):475-81.

30. Kyngäs H, Lahdenperä T. Compliance of patients with hypertension and associated factors. J Adv Nurs. 1999;29(4):832-39.

31. Kanj M, Mitic W. Health literacy and health promotion. Prepared for: 7th Global Conference on Health Promotion, "Promoting Health and Development: Closing the Implementation Gap"; October 26-30, 2009; Nairobi, Kenya. World Health Organization. Available at: http://www.who.int/healthpromotion/conferences/7gchp/Track1_Inner.pdf. Accessed May 15, 2012

32. Martin LR, Williams SL, Haskard KB, Dimatteo MR. The challenge of patient adherence. Ther Clin Risk Manag. 2005;1(3):189-99. Available at: http:// www.ncbi.nlm.nih.gov/pmc/articles/PMC1661624/. Accessed May 15, 2012.

33. Kickbusch IS. Health literacy: addressing the health and education divide. Health Promot Int. 2001;16(3):289-97. Available at: http://heapro. oxfordjournals.org/content/16/3/289.full. Accessed May 15, 2012.

34. Horne R, Weinman J. Patients' beliefs about prescribed medicines and their role in adherence to treatment in chronic physical illness. J Psychosom Res. 1999;47(6):555-67.
35. Macer DRJ. Bioethics in Japan and East Asia. Turkish J Med Ethics. 2001;9:70-77. Available at: http://www.eubios.info/Papers/ASIABE.htm. Accessed May 15, 2012.

36. Yap KY, Chan A, Chui WK. Improving pharmaceutical care in oncology by pharmacoinformatics: the evolving role of informatics and the internet for drug therapy. Lancet Oncol. 2009;10(10):1011-19.

37. O'Connell P. Simple telehealth \& flo. National Health Service. Available at: https://groups.its-services.org.uk/display/simple/Home. Accessed May 15, 2012

38. Weaver A, Young AM, Rowntree J, et al. Application of mobile phone technology for managing chemotherapy-associated side-effects. Ann Oncol. 2007;18(11):1887-92. Available at: http://annonc.oxfordjournals.org/content/18/11/1887.full. Accessed May 15, 2012.

39. Partridge AH, Avorn J, Wang PS, Winer EP. Adherence to therapy with oral antineoplastic agents. J Natl Cancer Inst. 2002;94(9):652-61. Available at: http://jnci.oxfordjournals.org/content/94/9/652.full. Accessed May 15, 2012.

40. Brearley SG, Clements CV, Molassiotis A. A review of patient selfreport tools for chemotherapy-induced nausea and vomiting. Support Care Cancer. 2008;16(11):1213-29. Available at: http://www.springerlink.com/ content/2795104354531700/fulltext.html. Accessed May 15, 2012.

41. Farmer KC. Methods for measuring and monitoring medication regimen adherence in clinical trials and clinical practice. Clin Ther. 1999;21(6):107490; discussion 1073.

42. Osterberg L, Blaschke T. Adherence to medication. N Engl J Med. 2005;353(5):487-97.

Date of chemotherapy: Cycle No:

Day 1 (24 hours after chemotherapy) (Date: )

VOMITING RESPONSE

State the number of times you vomited today:

\section{NAUSEA RESPONSE}

Mark with a cross (below the number) to reflect the intensity of nausea experienced

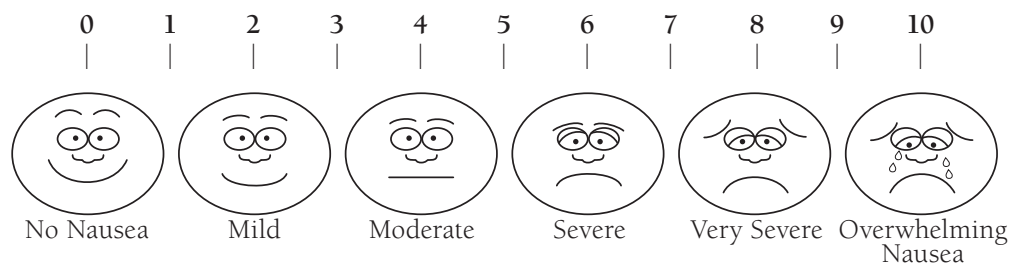

Please mark with a cross in the respective columns to indicate medication being taken

\begin{tabular}{|l|l|l|l|l|}
\hline Antiemetics Prescribed & Morning & Noon & Evening & Night \\
\hline Kytril (granisetron) or Zofran (ondansetron) & & & & \\
\hline Dexamethasone & & & & \\
\hline Emend (aprepitant tripack) & & & & \\
\hline Maxalon (metoclopramide) & & & & \\
\hline
\end{tabular}

